\title{
Risk Factors of Hypocalcemic Patients at Surgical Intensive Care Unit of Zagazig University Hospitals
}

Zeinab Ibrahim El hossary, Sahar Mohammed Saad Eldin, Heba Helmy Matar, Ibrahim Abdel-Halim Askar Anesthesia and Surgical Intensive Care Department, Faculty of Medicine, Zagazig University, Egypt

*Corresponding author: Ibrahim A. Askar, Mobile: (+2)01064377460, Email: ebrahimasker96@gmail.com

\begin{abstract}
Background: Hypocalcemia may be present as an asymptomatic laboratory finding or as a severe life-threatening condition. Objective: The study aimed to estimate incidence rate of hypocalcemia and to identify risk factors associated with hypocalcemia in patients of Surgical Intensive Care Unit of Zagazig University Hospitals.

Patients and methods: This study involved 310 patients who enrolled to Surgical Intensive Care Unit, Zagazig University Hospitals over a period of six months. Total serum calcium concentration and ionized calcium concentration were measured.

Results: The distribution of the studied cases according to admission diagnosis, $40 \%$ of the studied cases were admitted to ICU due to sepsis and septic shock, $16 \%$ polytrauma, $10 \%$ respiratory failure, $10 \%$ post-operative monitoring, $6 \%$ with ICH, $6 \%$ with uncontrolled HTN, $4 \%$ with ischemic stroke, $2 \%$ pancreatitis, $2 \%$ dehydration and electrolyte imbalance, $2 \%$ DKA and one case due to organophosphorus poisoning and $1 \%$ rhabdomyolysis. There was statistically significant negative correlation between GCS score and Ca total and ionized at 3rd day. However, a statistically significant positive correlation was detected between $\mathrm{Ph}$ and $\mathrm{Ca}$ total at 3rd day. Only sepsis, septic shock, hypertensive crisis, aminoglycosides, respiratory failure and APACHE score were significant risk factors for hypocalcemia.

Conclusion: Hypocalcemia is more common in cases with sepsis and septic shock, hypertensive crisis, respiratory failure and cases with electrolyte disturbance.
\end{abstract}

Keywords: Hypocalcemia, Ill patients, ICU, APACHE score.

\section{INTRODUCTION}

Hypocalcemia may be present as an asymptomatic laboratory finding or as a severe lifethreatening condition. Distinguishing acute from chronic hypocalcemia and asymptomatic from severely symptomatic hypocalcemia is important for determining appropriate therapy. In case of acute hypocalcemia, rapid treatment may be required. In contrast, chronic hypocalcemia may be well tolerated, but treatment is necessary to avoid long-term complications ${ }^{(\mathbf{1}, 2)}$. In extreme cases of hypocalcemia, bronchospasm and laryngospasm with stridor may occur. Muscle symptoms can be so severe as to present with a polymyositis-like picture with elevated muscle isoenzymes. These symptoms are corrected by calcium replacement ${ }^{(3)}$.

Hypocalcemia can also occur in patients treated with some chemotherapeutic drugs. For example, cisplatin can induce hypocalcemia by causing hypomagnesemia, and combination therapy with 5fluorouracil and leucovorin can cause mild hypocalcemia, possibly by decreasing calcitriol production. In addition, acute kidney injury and hypocalcemia have been reported as adverse effects in patients receiving the programmed cell death protein 1 (PD-1) inhibitors nivolumab and pembrolizumab ${ }^{(4)}$. Hypocalcemia may result from the treatment of hypercalcemia with bisphosphonates, particularly zoledronic acid, which is significantly more potent than other bisphosphonates in suppressing the formation and function of osteoclasts. Patients who are affected appear to lack an adequate PTH response to decreasing serum calcium levels ${ }^{(5)}$.

Hypocalcemia and osteomalacia have been described with prolonged therapy with anticonvulsants (e.g. phenytoin, phenobarbital). The mechanisms differ according to the class of anticonvulsants; for example, phenytoin induces cytochrome P450 enzymes and enhances vitamin D catabolism ${ }^{(6)}$.

Some studies used corrected calcium values while others measured ionized calcium. It is also not clear if calcium measurements were made for diagnostic, screening, homeostatic or daily routine purposes. The only thing that is evident at present is that some $50 \%$ of critically ill patients in an ICU will have hypocalcemia at some moment at some day during their stay ${ }^{(7)}$.

The aim of the study was to estimate incidence rate of hypocalcemia and to identify risk factors associated with hypocalcemia in patients of Surgical Intensive Care Unit of Zagazig University Hospitals.

\section{PATIENTS AND METHODS}

This study involved 310 patients who enrolled to Surgical Intensive Care Unit, Zagazig University Hospitals over a period of six month.

Inclusion criteria: Patients in age above 18 years old who admitted to Surgical Intensive Care Unit of Zagazig University Hospitals with normal calcium level over period of 6 months.

Exclusion criteria: Patients with previous history of hospital admission within 2 weeks before presentation, 
patients with hypocalcemia on admission, supplementation with vitamin D therapy at time of admission. Current treatment for malignancy and known parathyroid disease.

\section{Methods:}

Convenience sampling method was used in this study. All patients who were admitted to Intensive Care Unit of Zagazig University Hospitals and patients of other Intensive Care Units over a period of six months.

Total serum calcium concentration was measured colorimetrically, whereas the serum ionized calcium concentration was measured using an ion-selective electrode method. Total and ionized calcium were evaluated after resuscitation at 1 st and 3rd days of initiation of nutritional support and at 5 days after admission to ICU. Patients' albumin, calcium, magnesium, phosphorus and blood urea and creatinine were measured.

\section{Ethical approval:}

The study was approved by the Ethical Committee of Zagazig Faculty of Medicine. An informed consent was obtained from all patients in this research. Every patient received an explanation for the purpose of the study. All given data were used for the current medical research only. This work has been carried out in accordance with The Code of Ethics of the World Medical Association (Declaration of Helsinki) for studies involving humans.

\section{Statistical analysis}

Data were analyzed using Statistical Package for the Social Sciences (SPSS, Version 25, Chicago, IL). Quantitative variables were expressed as mean \pm SD and qualitative variables as percent. KolmogrovSmirnove test, Pearson correlation coefficient test, Independent $t$ test, $\chi^{2}$ test and linear regression were used. $\mathrm{P}$ value $\leq 0.05$ was considered statistically significant (S). $\mathrm{P}>0.05$ : Non-significant (NS), and $\mathrm{P}<$ 0.01: Highly significant (HS).

\section{RESULTS}

Over a period of six month, we evaluated a sample of 310 patients who were admitted to ICU and their calcium level was measured. We found $32.25 \%$ $(n=100)$ of patients showing hypocalcemia. Incidence of hypocalcemia was $41 \%$ in 3rd day of admission and $59 \%$ in 5th day of admission. Regarding onset of hypocalcemia, $41 \%$ of the cases developed hypocalcemia on the third day of follow up and 59\% of the studied cases developed hypocalcemia on the 5th day of follow up (Table 1).

Regarding distribution of the studied cases according to admission diagnosis, $40 \%$ of the studied cases were admitted to ICU due to sepsis and septic shock, $16 \%$ due to polytrauma, $10 \%$ due to respiratory failure, $10 \%$ due to post-operative monitoring, $6 \%$ with $\mathrm{ICH}, 6 \%$ with uncontrolled HTN, $4 \%$ with ischemic stroke, $2 \%$ due to pancreatitis, $2 \%$ due to dehydration and electrolyte imbalance, $2 \%$ due to DKA, one case due to organophosphorous poisoning and $1 \%$ due to rhabdomyolysis (Table 2).

The distribution of the studied cases according to medications given in ICU revealed that $82 \%$ of the studied cases were treated with heparin, $79 \%$ with PPI, $21 \%$ with diuretics and $18 \%$ with aminoglycosides (Table 3).

There is statistically significant negative correlation between GCS score and Ca total and ionized at 3rd day $[(\mathrm{r}=-0.231, \mathrm{p}=0.021)$ and $(\mathrm{r}=-0.313$, $\mathrm{p}=0.002)]$ as shown in table (4). However, a statistically significant positive correlation was detected between $\mathrm{Ph}$ and $\mathrm{Ca}$ total at 3rd day $(\mathrm{r}=0.224, \mathrm{p}=0.025)$ as shown in figure (1).

Only sepsis, septic shock ( $\mathrm{p}=0.02)$, hypertensive crisis $(\mathrm{p}=0.02)$, aminoglycosides $(\mathrm{p}=0.014)$, respiratory failure $(\mathrm{p}=0.03)$ and APACHE score $(p=0.02)$ were significant risk factors for hypocalcemia. The other studied variables showed non-significant values (Table 5).

Table (1): Incidence and onset of hypocalcemia

\begin{tabular}{|l|c|c|}
\hline & at $3^{\text {rd }}$ day & at $^{\text {th }}$ day \\
\hline Hypocalcemia & $41(41.0 \%)$ & $59(59 \%)$ \\
\hline
\end{tabular}

Table (2): distribution of the studied cases according to admission diagnosis

\begin{tabular}{|l|c|c|}
\hline & $\mathbf{n = 1 0 0}$ & $\mathbf{\%}$ \\
\hline ICH & 6 & 6.0 \\
\hline Ischemic stroke & 4 & 4.0 \\
\hline Polytrauma & 16 & 16.0 \\
\hline Organophosphorus poisoning & 1 & 1.0 \\
\hline Sepsis, septic shock & 40 & 40.0 \\
\hline Hypertensive crisis & 6 & 6.0 \\
\hline Rhabdomyolysis & 1 & 1.0 \\
\hline $\begin{array}{l}\text { Dehydration, electrolyte } \\
\text { imbalance }\end{array}$ & 2 & 2.0 \\
\hline Post-operative monitoring & 10 & 10.0 \\
\hline Pancreatitis & 2 & 2.0 \\
\hline Respiratory failure & 10 & 10.0 \\
\hline DKA & 2 & 2.0 \\
\hline
\end{tabular}

Table (3): Distribution of the studied cases according to medications given in ICU

\begin{tabular}{|l|c|c|}
\hline & $\mathbf{n = 1 0 0}$ & \% \\
\hline PPI & 79 & 79.0 \\
\hline Aminoglycosides & 18 & 18.0 \\
\hline Heparin (ufh+lmwh) & 82 & 82.0 \\
\hline Diuretics & 21 & 21.0 \\
\hline
\end{tabular}


Table (4): Correlation between total and ionized calcium with age, GCS, duration of ICU stay and laboratory findings among studied cases

\begin{tabular}{|c|c|c|c|}
\hline & & Ca Total at $3^{\text {rd }}$ day & Ca ionized at $3^{\text {rd }}$ day \\
\hline \multirow[t]{2}{*}{ age/years } & $\mathrm{r}$ & .132 & .130 \\
\hline & $\mathrm{p}$ & .191 & .198 \\
\hline \multirow[t]{2}{*}{ GCS } & $\mathrm{r}$ & $-.231^{*}$ & $-.313^{*}$ \\
\hline & $\mathrm{p}$ & .021 & .002 \\
\hline \multirow[t]{2}{*}{ duration of ICU stay/ days } & $\mathrm{r}$ & .075 & .146 \\
\hline & $\mathrm{p}$ & .460 & .146 \\
\hline \multirow[t]{2}{*}{ Creatinine } & $\mathrm{r}$ & .016 & .079 \\
\hline & $\mathrm{p}$ & .872 & .436 \\
\hline \multirow[t]{2}{*}{ Urea } & $\mathrm{r}$ & .121 & .109 \\
\hline & $\mathrm{p}$ & .231 & .282 \\
\hline \multirow[t]{2}{*}{ Albumin } & $\mathrm{r}$ & -.102 & .050 \\
\hline & $\mathrm{p}$ & .311 & .620 \\
\hline \multirow[t]{2}{*}{$\mathbf{P h}$} & $\mathrm{r}$ & $.224^{*}$ & .183 \\
\hline & $\mathrm{p}$ & .025 & .068 \\
\hline \multirow[t]{2}{*}{ Mg } & $\mathrm{r}$ & .045 & .083 \\
\hline & $\mathrm{p}$ & .659 & .413 \\
\hline
\end{tabular}

r: Spearman correlation co-efficient, ${ }^{*}$ statistically significant if $\mathrm{p}<0.05$

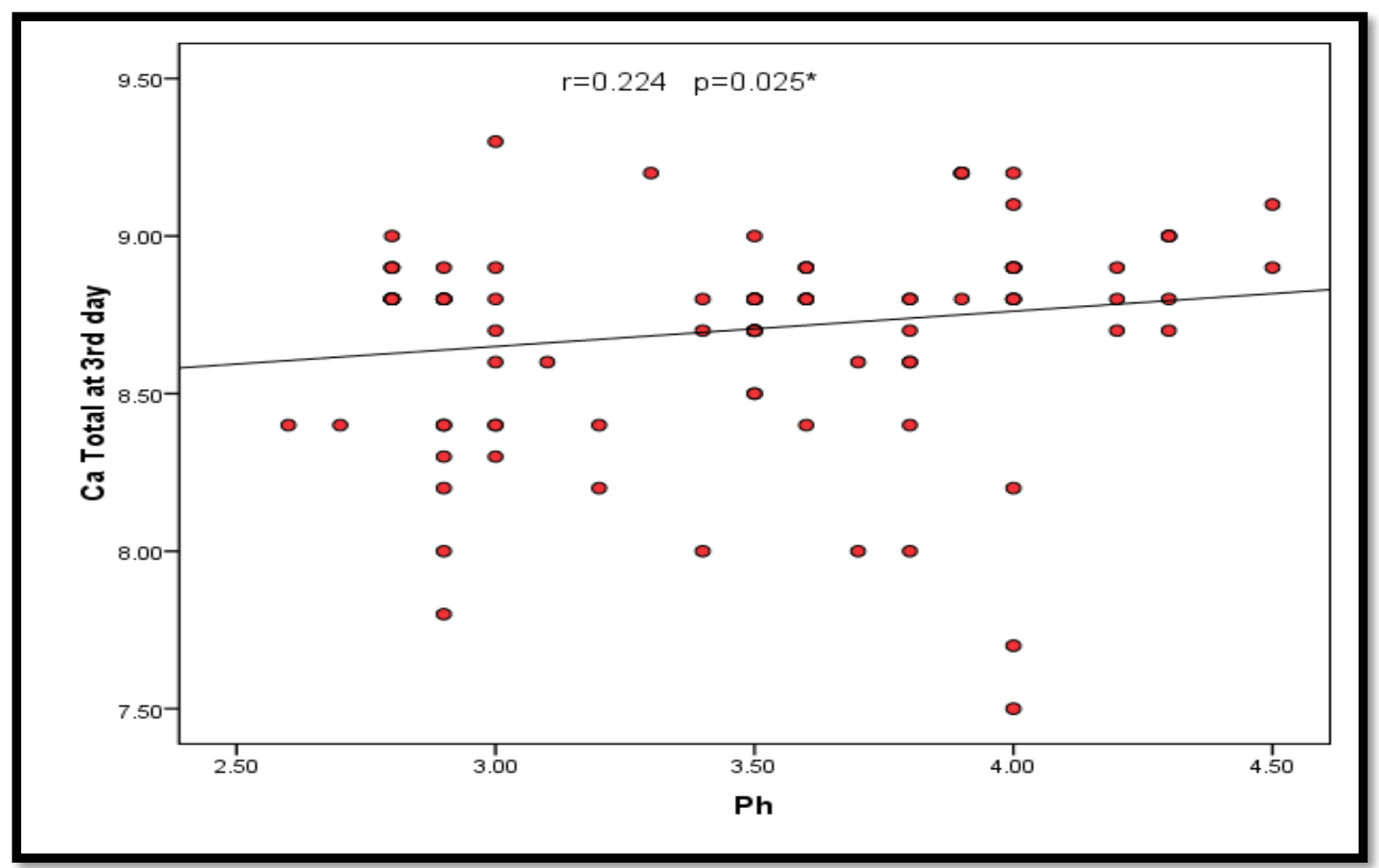

Figure (1): Scatter diagram showing correlation between $\mathrm{Ph}$ and $\mathrm{Ca}$ total at $3^{\text {rd }}$ day 
Table (5): Risk factors of hypocalcemia among cases admitted to ICU among studied cases

\begin{tabular}{|c|c|c|c|}
\hline Risk factors & $\begin{array}{c}\text { Total cases } \\
\mathbf{n}=\mathbf{1 0 0}\end{array}$ & $\begin{array}{c}\text { Hypocalcemia at } \\
\text { third day } \\
n=41(41 \%)\end{array}$ & $\begin{array}{c}\text { Test of } \\
\text { significance }\end{array}$ \\
\hline $\begin{array}{l}\text { Age/years } \\
20-40 \\
>40-60 \\
>60-80\end{array}$ & $\begin{array}{l}34 \\
40 \\
26\end{array}$ & $\begin{array}{l}15(44.1 \%) \\
14(35.0 \%) \\
12(46.2 \%)\end{array}$ & $\begin{array}{l}\mathrm{P}=0.875 \\
\mathrm{P}=0.365 \\
\mathrm{P}=0.765\end{array}$ \\
\hline $\begin{array}{l}\text { Sex } \\
\text { Male } \\
\text { Female }\end{array}$ & $\begin{array}{l}49 \\
51\end{array}$ & $\begin{array}{l}18(36.7 \%) \\
23(45.1 \%)\end{array}$ & $\begin{array}{l}\mathrm{P}=0.395 \\
\mathrm{P}=.0422\end{array}$ \\
\hline $\begin{array}{l}\text { Duration of ICU stay/days } \\
3-6 \\
7-10 \\
11-14\end{array}$ & $\begin{array}{l}34 \\
47 \\
19\end{array}$ & $\begin{array}{c}19(44.2 \%) \\
19(40.4 \%) \\
3(30.0 \%)\end{array}$ & $\begin{array}{l}\mathrm{P}=0.412 \\
\mathrm{P}=0.539 \\
\mathrm{P}=0.225\end{array}$ \\
\hline $\mathrm{ICH}$ & 6 & $3(50 \%)$ & $\mathrm{P}=0.686$ \\
\hline Ischemic stroke & 4 & $0(0.0)$ & $\mathrm{P}=0.142$ \\
\hline Polytrauma & 16 & $5(31.2 \%)$ & $\mathrm{P}=0.387$ \\
\hline Organophosphorus poisoning & 1 & $1(100 \%)$ & $\mathrm{P}=0.41$ \\
\hline Sepsis, septic shock & 40 & $22(55 \%)$ & $\mathrm{P}=0.02 *$ \\
\hline Hypertensive crisis & 6 & $5(83.3 \%)$ & $\mathrm{P}=0.02 *$ \\
\hline Rhabdomyolysis & 1 & $1(100 \%)$ & $\mathrm{P}=0.41$ \\
\hline Dehydration, electrolyte imbalance & 2 & $0(0.0)$ & $\mathrm{P}=0.16$ \\
\hline Post-operative monitoring & 10 & $2(20.0 \%)$ & $\mathrm{P}=0.155$ \\
\hline Pancreatitis & 2 & $1(50.0 \%)$ & $\mathrm{P}=1.0$ \\
\hline Respiratory failure & 10 & $1(10.0 \%)$ & $\mathrm{P}=0.03^{*}$ \\
\hline DKA & 2 & $0(0.0 \%)$ & $\mathrm{P}=0.51$ \\
\hline \multicolumn{4}{|l|}{ Medications } \\
\hline PPI & 79 & $31(39.2 \%)$ & $\mathrm{P}=0.488$ \\
\hline Aminoglycosides & 18 & $12(66.7 \%)$ & $\mathrm{P}=0.014^{*}$ \\
\hline Heparin(ufh+lmwh) & 82 & $32(39.0 \%)$ & $\mathrm{P}=0.391$ \\
\hline Diuretics & 21 & $11(52.4 \%)$ & $\mathrm{P}=0.233$ \\
\hline APACHE score & median (range) & $25(9-50)$ & $\mathrm{p}=0.02 *$ \\
\hline
\end{tabular}

$\chi^{2}=$ Chi-Square test, FET: Fischer exact test, *statistically significant (if $\mathrm{p} \leq 0.05$ )

\section{DISCUSSION}

The first clinical observations and studies in hypocalcemic critically ill patients date back to the early 70 's and 80's of the last century. The incidence of hypocalcemia in critically ill patients varies widely depending on the different underlying diseases and comorbidity. In an analysis of 12 studies performed between 1988 and 2014 Aberegg ${ }^{(8)}$ believes that the incidence of hypocalcemia in critically ill patients ranges from $50-88 \%{ }^{(8)}$.

The aim of this study is to estimate the incidence rate and to identify risk factors of hypocalcemia in patients of Surgical Intensive Care Unit of Zagazig University Hospitals. The study was conducted over a period of six month and included 310 patients.

The incidence of hypocalcemia in critically ill patients varies widely depending on the different underlying diseases and comorbidity. Also, some studies used corrected calcium values while others measured ionized calcium. It is also not clear if the calcium measurements were made for diagnostic, screening, homeostatic or daily routine purposes ${ }^{(9)}$.
In our study, no significant correlation was detected between age and serum calcium levels ( $p$ > $0.05)$. This agrees with Steele $\boldsymbol{e t} \boldsymbol{a l}{ }^{(\mathbf{1 0 )}}$ who showed that there was no significant difference in the mean age between cases with hypocalcemia and normocalcemia.

In the current study, there was a significant negative correlation between serum calcium levels and GCS. In this study, the mean serum magnesium level in the included cases with hypocalcemia was $1.88 \mathrm{mg} / \mathrm{dl}$, no significant correlation was detected between magnesium and calcium levels in the current study that is in accordance with Iqbal $\boldsymbol{e t} \boldsymbol{a l} .{ }^{(\mathbf{1 1 )}}$ who reported that there was no correlation of magnesium with ionized calcium level. In contrast with our findings, Steele $\boldsymbol{e t}$ $\boldsymbol{a l} .{ }^{\mathbf{( 1 0})}$ showed that serum magnesium level was significantly lower in cases with low calcium levels indicating positive statistical correlation.

A report stated other drug groups as a direct risk factors for the development of that complication like calcium chelators, bisphosphonates, denosumab, cinacalcet, foscarnet, fluoride poisoning, and some chemotherapy regimens ${ }^{\left({ }^{(2)}\right)}$. On the other hand, multiple 
reports stated that hypocalcemia is often found in acute pancreatitis and is an indicator of poor prognosis. For the majority of patients, hypocalcemia reflects a hypoalbuminemic state. True hypocalcemia has been attributed to rampant lipolysis induced by pancreatic lipase and subsequent saponification with calcium. An animal model of pancreatitis challenges this mechanism (13). Moreover, hypocalcemia in the ICU is rarely caused by primary hypoparathyroidism. However, sepsis and systemic inflammatory response syndrome (SIRS) are commonly associated with hypocalcemia, which is caused in part by the impaired secretion and action of PTH and the failure to synthesize calcitriol ${ }^{(14)}$.

In this study, the mean serum phosphorous level in the included cases was $3.46 \mathrm{mg} / \mathrm{dl}$. It had a significant positive correlation with total calcium levels on the $3^{\text {rd }}$ day $(r=0.224-p=0.025)$. However, the ionized calcium levels did not show that significant correlation. On the other hand, there was a study showed that serum phosphorous level was significantly higher in the hypocalcemic group as compared with normocalcemic group ${ }^{(10)}$.

In this study, the mean serum albumin level in the cases was $3.43 \mathrm{~g} / \mathrm{dl}$. No significant correlation was detected between albumin and calcium levels $(p>0.05)$. Contrarily, other study showed that serum albumin level was significantly lower in the hypocalcemic group as compared to normocalcemic group ${ }^{\mathbf{1 0})}$.

The difference in results regarding correlation between magnesium, albumin and phosphorus with calcium may be because of the included larger number of patient $(1,038)$ and depending on ionized calcium only which was measured in the $1^{\text {st }}$ four days of admission. Therefore, Calcium chloride $10 \%$ solution delivers higher amounts of calcium and is advantageous when rapid correction is needed, but it should be administered via central venous access. Calcium infusion drips should be started at $0.5 \mathrm{mg} / \mathrm{kg} / \mathrm{hr}$ and increased to $2 \mathrm{mg} / \mathrm{kg} / \mathrm{hr}$ as needed, with an arterial line placed for frequent measurement of ionized calcium ${ }^{(15)}$.

It could be recommended to measure serum calcium every 4-6 hours to maintain serum calcium levels at $8-9 \mathrm{mg} / \mathrm{dl}$. If low albumin is also present, ionized calcium should be monitored. Further evaluation and observation of the patients. Patients with cardiac arrhythmias or patients on digoxin therapy need continuous electrocardiographic (ECG) monitoring during calcium replacement because calcium potentiates digitalis toxicity. Identify and treat the cause of hypocalcemia and taper the infusion ${ }^{(16)}$.

\section{CONCLUSION}

Hypocalcemia is more common in cases with sepsis and septic shock, hypertensive crisis, respiratory failure and cases with electrolyte disturbance.
Financial support and sponsorship: Nil. Conflict of interest: Nil.

\section{REFERENCES}

1. Bove-Fenderson E, Mannstadt M (2018): Hypocalcemic disorders. Best Practice \& Research Clinical Endocrinology \& Metabolism, 32 (5): 639-656.

2. Zaloga G, Chernow B (1987): The multifactorial basis for hypocalcemia during sepsis: studies of the parathyroid hormone-vitamin D axis. Annals of Internal Medicine, 107 (1): 36-41.

3. Fong J, Khan A (2012): Hypocalcemia: updates in diagnosis and management for primary care. Canadian Family Physician, 58 (2): 158-162.

4. Liamis G, Milionis H, Elisaf M (2009): A review of drug-induced hypocalcemia. Journal of Bone and Mineral Metabolism, 27 (6): 635-642.

5. Drake M, Clarke B, Khosla S (2008): Bisphosphonates: mechanism of action and role in clinical practice. In Mayo Clinic Proceedings. Elsevier.

Pp: 1032-1045. $\quad$ https://go.drugbank. com/articles/A40226

6. Neels H, Sierens A, Naelaerts K et al. (2004): Therapeutic drug monitoring of old and newer antiepileptic drugs. Clinical Chemistry and Laboratory Medicine, 42 (11): 1228-1255.

7. Baird G (2011): Ionized calcium. Clinica Chimica Acta., 412 (9-10): 696-701.

8. Aberegg $S$ (2016): Ionized calcium in the ICU: should it be measured and corrected?. Chest, 149 (3): 846-855.

9. Naafs M (2017): Hypocalcemia in the Critically Ill: A Mini-Review. Endocrinol Metab Int J., 5 (4): 130-134.

10. Steele T, Kolamunnage-Dona $\mathrm{R}$, Downey $\mathrm{C}$ et al. (2013): Assessment and clinical course of hypocalcemia in critical illness. Critical Care, 17 (3): 1-10.

11. Iqbal M, Rehmani R, Hijazi M et al. (2008): Hypocalcemia in a Saudi intensive care unit. Annals of Thoracic Medicine, 3 (2): 57-63.

12. Reddi A (2016): Renal Pharmacology. Absolute Nephrology Review, 16: 313-340.

13. Kelly A, Levine $M$ (2013): Hypocalcemia in the critically ill patient. Journal of Intensive Care Medicine, 28(3): 166-177.

14. Holowaychuk M, Martin L (2007): Review of hypocalcemia in septic patients. Journal of Veterinary Emergency and Critical Care, 17 (4): 348-358.

15. Krenz J, Kaakeh Y (2018): An overview of hyperinsulinemic-euglycemic therapy in calcium channel blocker and $\beta$-blocker overdose. Pharmacotherapy: The Journal of Human Pharmacology and Drug Therapy, 38 (11): 1130-1142.

16. Ardehali S, Dehghan S, Baghestani A et al. (2018): Association of admission serum levels of vitamin D, calcium, Phosphate, magnesium and parathormone with clinical outcomes in neurosurgical ICU patients. Scientific Reports, 8 (1): 1-8. 